\title{
Some observations on the response of normal human sigmoid colon to drugs in vitro
}

\author{
P. G. WRIGHT AND J. J. SHEPHERD
}

From the Makerere University College, Kampala, Uganda

EDITORIAL SYNOPSIS These pharmacological studies indicate that human normal colonic muscle has adrenergic structures in it thought to be post-ganglionic sympathetic nerves and cholinergic structures assumed to be parasympathetic ganglion cells. It is suggested that anoxia may be an important factor in some of the tissue perforations in modifying pharmacological responses. The differing reactions of longitudinal and cellular muscle of the bowel to 5-hydroxytryptamine is demonstrated.

In Uganda there is a high incidence of megacolon in male Africans which shows an interesting tribal distribution. It has been considered that this results from chronic partial obstruction due to the possession of a long sigmoid colon with considerable mobility because the megacolon is discovered when patients present with an acute volvulus. However, we are by no means convinced that this theory is satisfactory as a general rule and we are seeking alternative explanations (Shepherd and Wright, 1965).

In Hirschsprung's disease the megacolon is considered to be the response of normal colon to obstruction caused by aganglionosis in the distal region. The megacolon is not itself morphologically abnormal (Swenson, Neuhauser, and Pickett, 1949; Bodian, Stephens, and Ward, 1949). On the other hand the megacolon in Chagas disease is said to result from hypersensitivity of the muscle and incoordination of activity which results from destruction of large numbers of ganglia in the myenteric plexuses following infestation with, Trypanosoma cruzei (Köberle, 1958). The megacolon itself is morphologically abnormal. Routine histopathology has not suggested any morphological basis for the megacolon we see in Kampala, either in the dilated or normal segments. Quantitative estimations of the ganglion cell density in the dilated region reveal no reduction (Böhm, 1965, personal communication) and Chagas disease has never been described in Africa. Complement-fixation tests carried out on serum from our patients have been negative. Hypertrophy of other organs so characteristic of Chagas disease has never been found in our cases so we have no reason to suspect this disease. Whitehouse and Kernohan (1948) found that ganglia were present to a normal degree in the secondary megacolon occurring in sigmoid carcinoma, intermittent volvulus, and enterocolitis.
As one of our lines of enquiry we are interested in the functional status of the nerve and muscle in normal and abnormal sigmoid colon. The myenteric plexuses of Auerbach and Meissner are considered to consist of parasympathetic neurones and are present in normal human colon. However, Fishlock and Parks (1963) examined circular muscle and Bucknell and Whitney (1964) longitudinal muscle from human colon in vitro and as a result of the response to chemical stimulation could find no evidence for the existence of parasympathetic cholinergic nerves. Is there a difference between man and other species in the nature and function of these plexuses or in their response to drugs? It is obviously necessary to re-examine these questions before we can look for pathological variations. We have, therefore, made observations on the response in vitro of both circular and longitudinal muscle from normal human sigmoid colon to certain drugs and have reached different conclusions to the previous authors.

Our material came from patients undergoing resection of a sigmoid megacolon. In most cases they had presented with volvulus, but an interval of three weeks to three months elapsed between relief of the obstructive phase by sigmoidoscopy and the resection. We have discussed elsewhere the criteria for the condition we recognize as megacolon (Shepherd and Wright, 1965) and tissue for these observations was not taken from colon that appeared in any way abnormal. The tissue whose response we are describing came from a region of sigmoid colon which appeared normal radiologically and histologically and which at laparotomy showed normal activity and no evidence of dilatation or hypertrophy. We have called this material 'normal' colon. Fishlock and Parks (1963) described colon in association with non-obstructive neoplastic disease but 
normal macroscopically and histologically as 'healthy' colon.

\section{METHODS}

Experiments were carried out on some 76 preparations of colon from 14 male African patients. They received no premedication with atropine and were anaesthetized with $\mathrm{N}_{2} \mathrm{O} / \mathrm{O}_{2}$ mixture. Adequate relaxation was secured with intramuscular d-tubocurarine or succinylcholine. The resected colon was immediately immersed in ice-cold gassed Krebs solution and removed to the laboratory. A short length of normal colon was then selected and cut off. It was opened along the border of one taenia and the mucosa removed rapidly under a dissecting microscope. As much as possible of the serosa was similarly removed. Parallel strips about $1 \frac{1}{2} \mathrm{~mm}$. in width were then cut from the taenia and from the circular muscle between two taenia. The taenia at the mesenteric border was usually selected to provide the longitudinal muscle specimens because here connective tissue is looser and more easily removed. During these proceedings the tissue was repeatedly bathed with ice-cold Krebs solution. The muscle strips were set up in organ baths at $36 \mathrm{C}$. in Krebs solution gassed with $95 \% \mathrm{O}_{2} / 5 \% \mathrm{CO}_{2}$ mixture. Recording was by means of a frontal writing lever, with a magnification of four times, which produced a load of $2 \mathrm{~g}$. upon the muscle.

About 40 minutes was allowed for equilibration before drugs were first added. Under these conditions both circular and longitudinal muscle exhibited tone and rhythmical activity though the taenia was more prone to occasional slow contractile activity and often showed nothing else. The drug responses to be described apply to both circular and longitudinal muscle unless it is stated otherwise.

The drugs used were: acetylcholine chloride, neostigmine methyl sulphate (Roche Products); adrenaline hydrochloride, dimethylphenylpiperazinium iodide (Parke Davis); noradrenaline bitartrate (Astra); hyoscine methonitrate (Pharmacia); pronethalol (I.C.I.); bretylium tosylate (Burroughs Wellcome); hexamethonium bromide, nicotine hydrogen tartrate (B.D.H.); 5-hydroxytryptamine creatinine sulphate (Sandoz); 1-methyl lysergic acid butanolamide (Sandoz).

All drug concentrations in this paper refer to the final concentration of the base in the bath fluid.

\section{RESULTS}

EFFECT OF NICOTINE AND DIMETHYLPHENYLPIPERAZINIUM (D.M.P.P.) Both the concentration of the drug and the time it was left in contact with the tissue affected the response. Concentrations of less than $10^{-5}$ and contact times of up to 1 minute invariably caused only inhibition. Concentrations of about $10^{-5}$ and longer contact times produced immediate inhibition later succeeded by contraction. With higher concentrations contraction more rapidly succeeded inhibition. Still higher concentrations

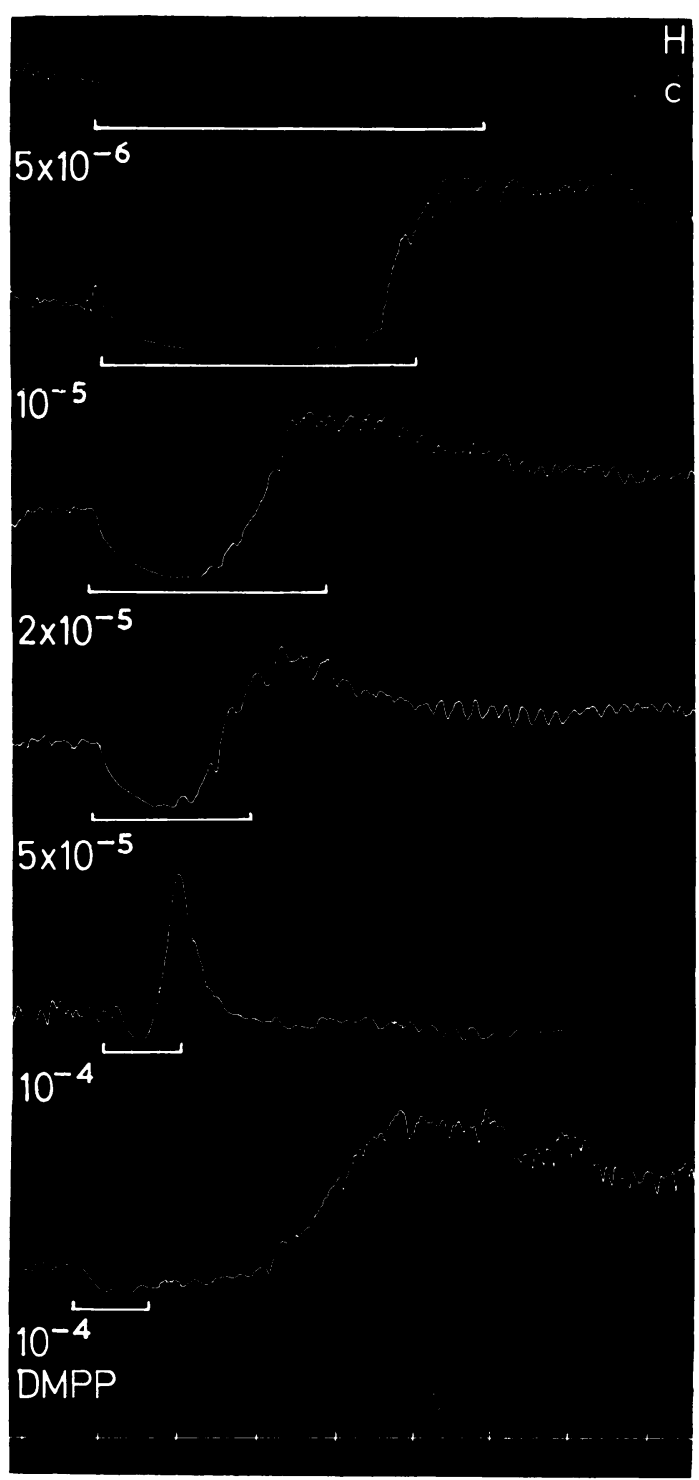

FIG. 1. Response of a circular muscle strip to D.M.P.P. Effect of variation of dose and contact time. Duration of drug contact is shown by the longitudinal bar in all records. Time interval one minute in all records.

caused inhibition succeeded immediately by contraction which was then shortly followed by inhibition. When this occurred it was some time before contraction could again be elicited by a further dose.

This sequence is illustrated in Figure 1. A circular 


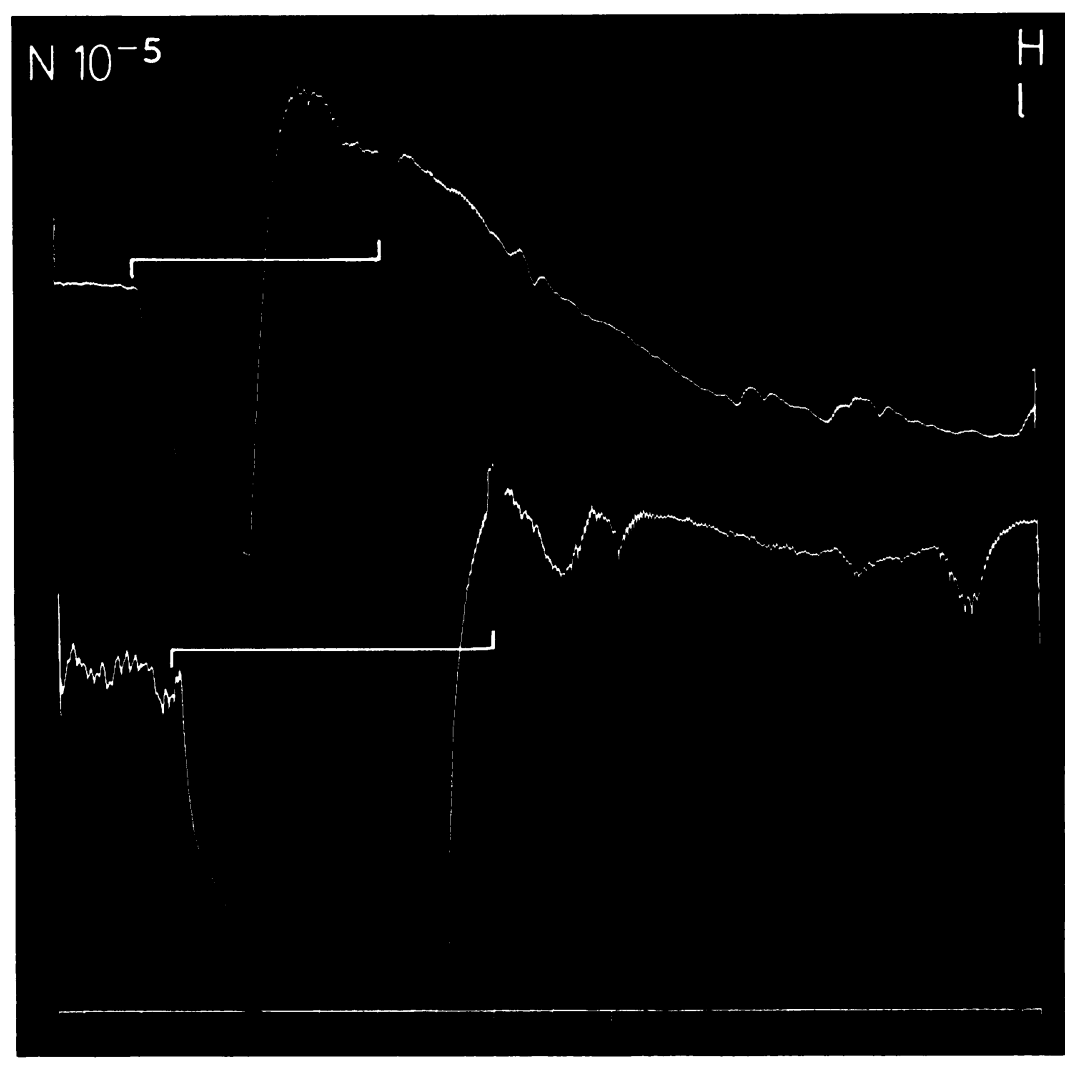

FIG. 2. Response of two adjacent strips of longitudinal muscle to nicotine $10^{-5}$.

muscle preparation was exposed to different concentrations of D.M.P.P. in a random fashion and the records subsequently arranged for the figure. The drug was washed out each time when contraction occurred and the bath fluid was renewed at minute intervals for 15 minutes when the next dose was added.

Figure 2 shows the response of two adjacent strips of longitudinal muscle to the same concentration of nicotine. Both yield a diphasic response but require different contact times.

Our observations suggest, therefore, that nicotine and D.M.P.P. can produce both inhibitory and contractile responses in both circular and longitudinal colonic muscle but that the actual response obtained in any instance depends on concentration, contact time, and the intrinsic properties of each preparation.

The analysis by previous authors of the response of colonic muscle in other species suggests that the initial inhibition is due to the release of a sympathetic transmitter from postganglionic structures and the contraction is the result of stimulation of parasympathetic ganglia. The inhibitory factor has the lower threshold but its effect can be overcome by the second factor.

Figure 3 shows that the concentration of nicotine which alone produces a diphasic response will produce only inhibition in the presence of hyoscine. In the presence of neostigmine inhibition is annulled and contraction is greater. It can also be seen that subsequent relaxation is hastened by neostigmine. This is a constant observation (Fig. 4) which suggests that ganglionic block may be facilitated under these conditions. Figure 4 demonstrates a similar sequence with D.M.P.P. and also that hexamethonium may block both responses.

These observations support the above suggestions, and we have attempted to test them further by influencing adrenergic and cholinergic factors but using concentrations and contact times of the test drug which do not cause ganglionic block.

Eight adjacent strips of muscle were set up in separate organ baths and a dose response curve to 


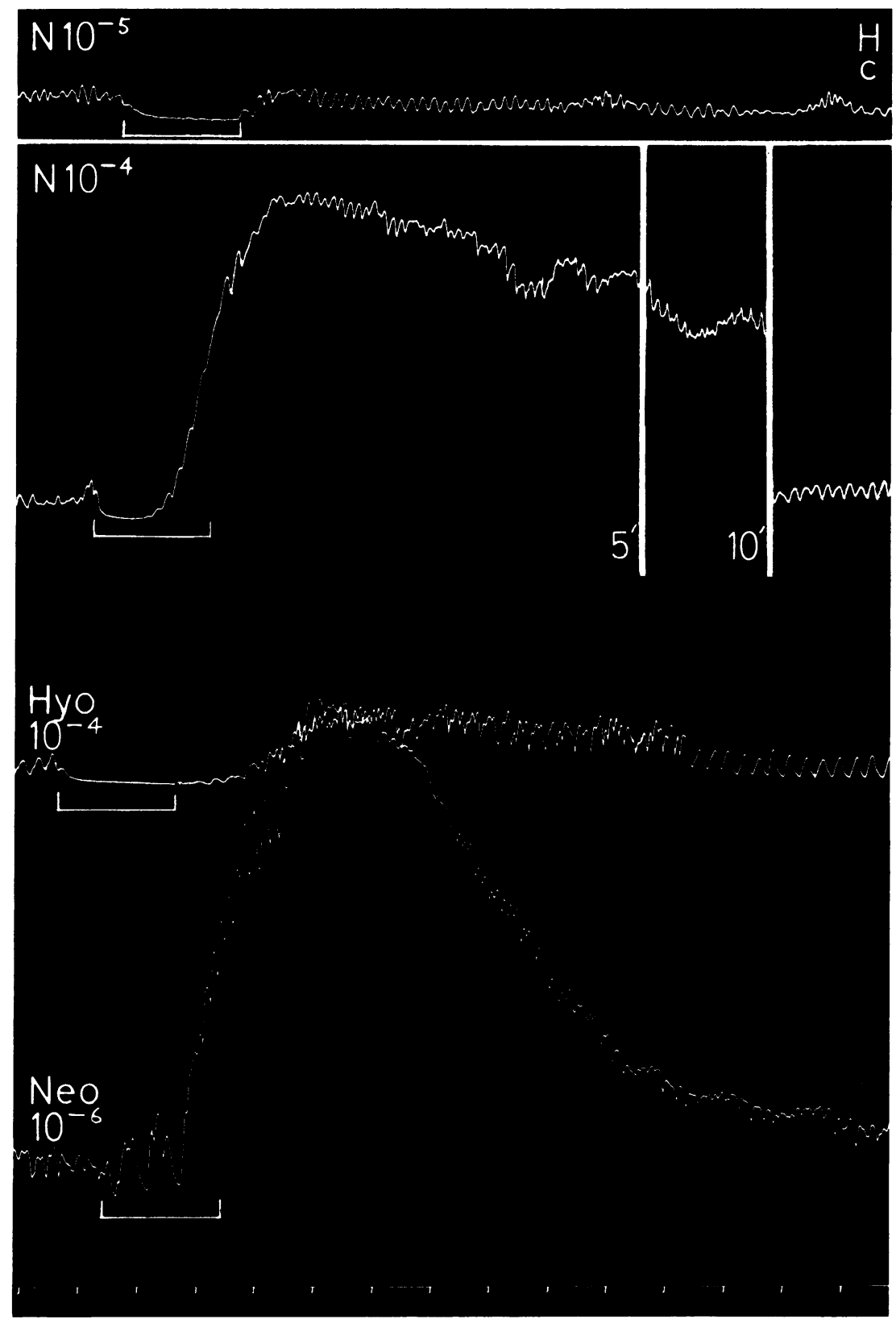

FIG. 3. Response of circular muscle to nicotine $10^{-5}$, nicotine $10^{-4}$, and the effect of hyoscine $10^{-4}$ and neostigmine $10^{-6}$ on the response to nicotine $10^{-4}$. Two breaks of five and $10 \mathrm{~min}$. are indicated. 


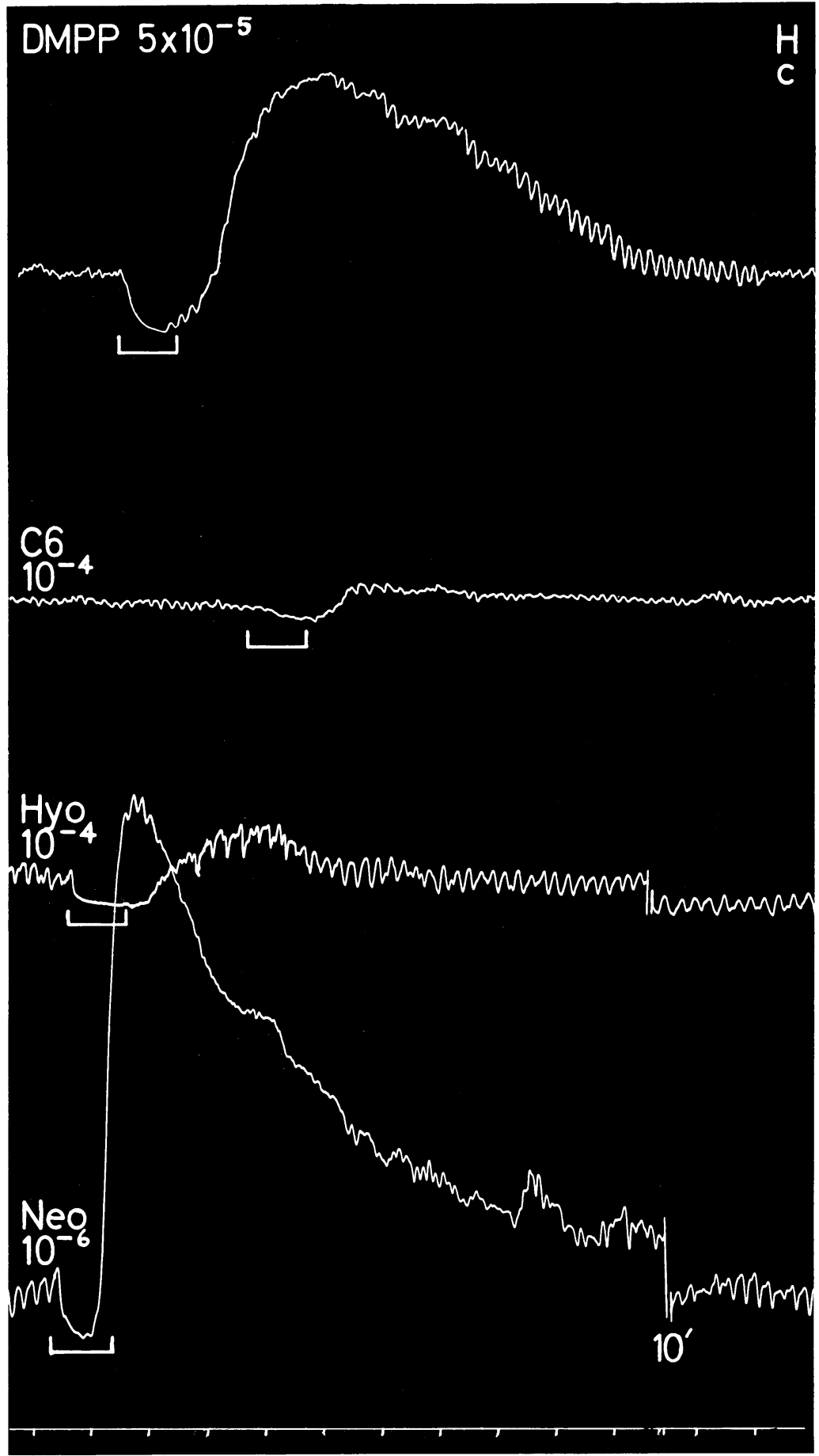

Ha. 4. Response of circular muscle to D.M.P.P. 5. I0 5 and the effect of hexamethonium I0 'and neostigmine $10^{-4}$ upon it. A break of 10 min. is indicated. 


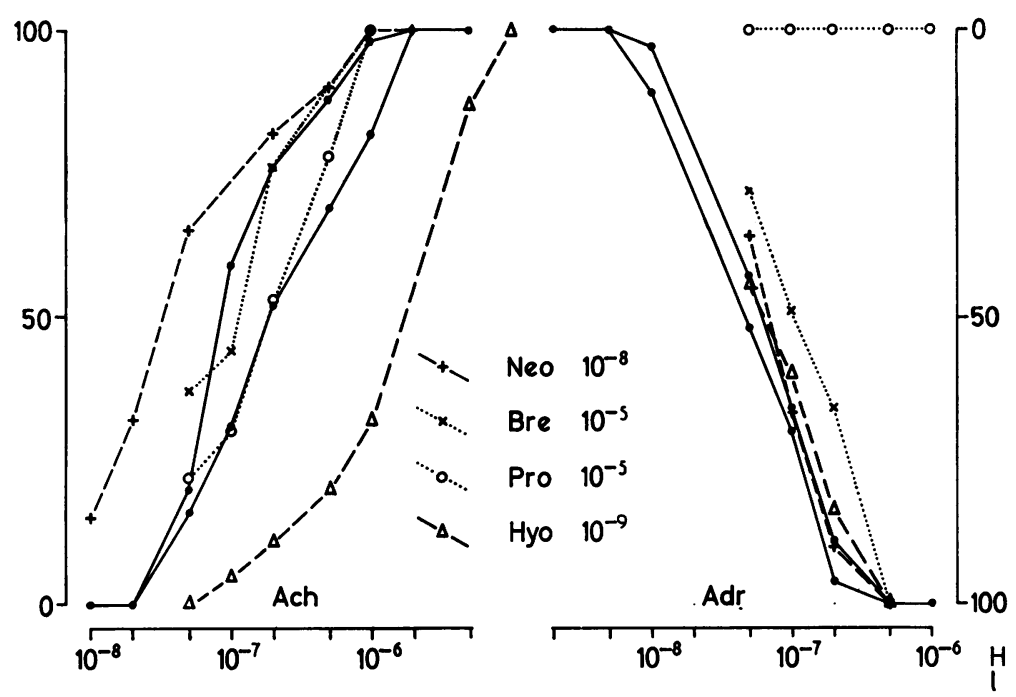

FIG. 5. Longitudinal muscle. Dose-response relationship for acetylcholine and adrenaline on eight parallel preparations. The continuous line encloses the maximum variation during eight hours. The broken lines show the relationship in the presence of the concentration of drug indicated. Ordinate = contraction of relaxation as percentage of the maximum; abscissa = acetylcholine or adrenaline concentration.

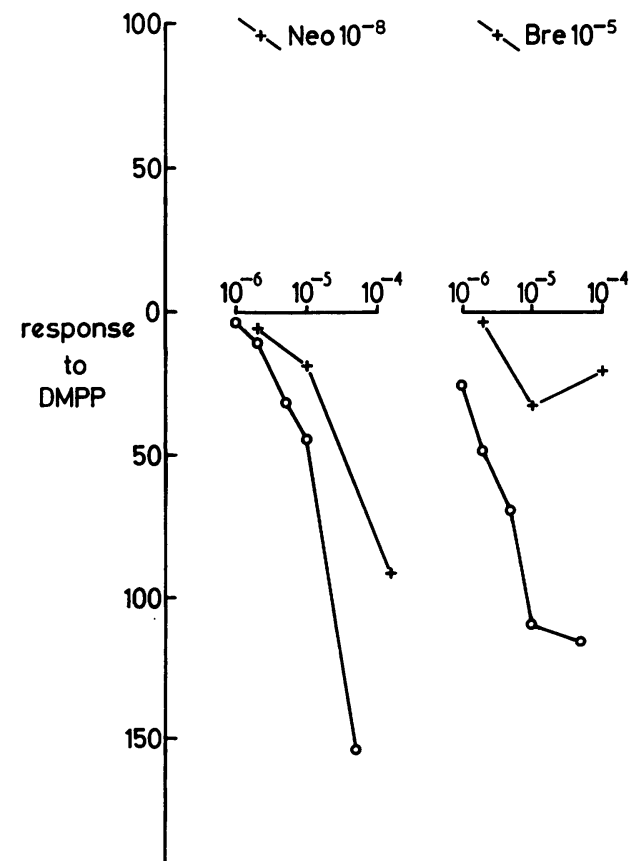

FIG. 6. $200^{\mathrm{L}}$
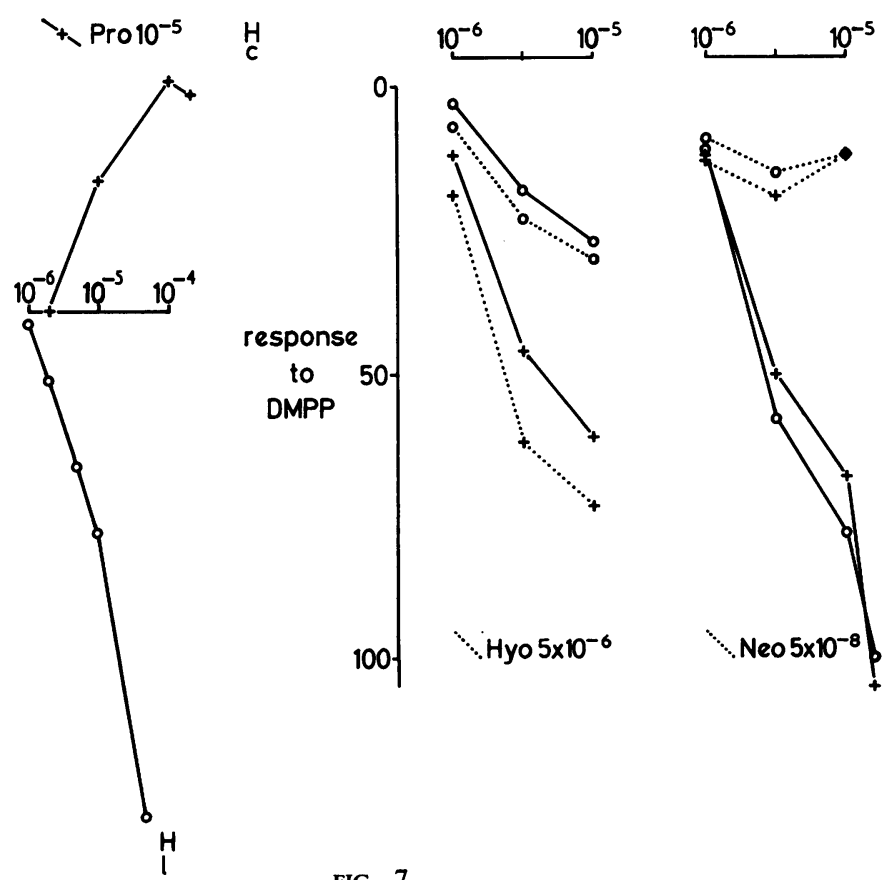

FIG. 7.

FIG. 6. Longitudinal muscle. Dose-response relationship for D.M.P.P. and the effect of neostigmine, bretylium, and pronethalol upon it in three preparations. Ordinate $=$ initial inhibitory or excitory response in arbitrary units of area; abscissa $=$ D.M.P.P. concentration.

FIG. 7. As Fig. 6. The effect of hyoscine and neostigmine on the response to D.M.P.P. in two preparations. 
acetycholine, adrenaline, and D.M.P.P. was obtained for each. Thirty seconds' contact time was allowed so that only a net inhibitory response was obtained with D.M.P.P. and this drug was not repeated at less than 15 -minute intervals to avoid possible paralytic effects. Half the preparations were then treated with neostigmine, pronethalol, bretylium, or hyoscine and after 30 minutes' contact the dose response relationships were reinvestigated on all preparations.

Figure 5 shows the range of variations of response to acetycholine and adrenaline in all preparations during the course of the experiment. It shows that neither pronethalol nor bretylium in the concentration used had much effect on the response to acetylcholine and that neither neostigmine nor hyoscine in the concentration used affected the response to adrenaline. The concentration of neostigmine and hyoscine had the expected effect on the acetylcholine response. The response to adrenaline was completely blocked by the concentration of pronethalol used while bretylium had a small apparent effect. We therefore suggest that the effects of these agents on the response to D.M.P.P. can be interpreted in terms of their action of the release in or response by the tissues to acetylcholine and adrenaline and not to unspecific side effects.

To measure the net inhibitory response to D.M.P.P. we have drawn the initial baseline through the monophasic or diphasic response and measured the area below it, the effective inhibition. This is because we are considering the release of, and response to, substances with opposing actions and time is as important a factor as extent of response. Where the net response was contraction it has been similarly assessed.

Figures 6 and 7 show that the initial inhibition caused by D.M.P.P. is reduced by neostigmine which favours the cholinergic mechanism and by bretylium which reduces the participation of the adrenergic mechanism. The inhibition is blocked by pronethalol which opposes the action of the adrenergic transmitter and contraction results. The inhibition is increased by hyoscine which opposes the cholinergic mechanism.

EFFECTS OF 5-HYDROXYTRYPTAMINE (5HT) Nicotine, D.M.P.P., and 5-hydroxytryptamine have all been reported to inhibit circular muscle from human colon. We have found that nicotine and D.M.P.P. can also cause it to contract. In one instance only we found that 5HT $10^{-8}$ caused contraction of circular muscle. This was a repeatable response which showed tachyphylaxis in the usual way and was blocked by 1-methyl lysergic acid butanolamide $10^{-6}$. We have only obtained inhibition with other specimens (Fig. 8) at all dose levels.

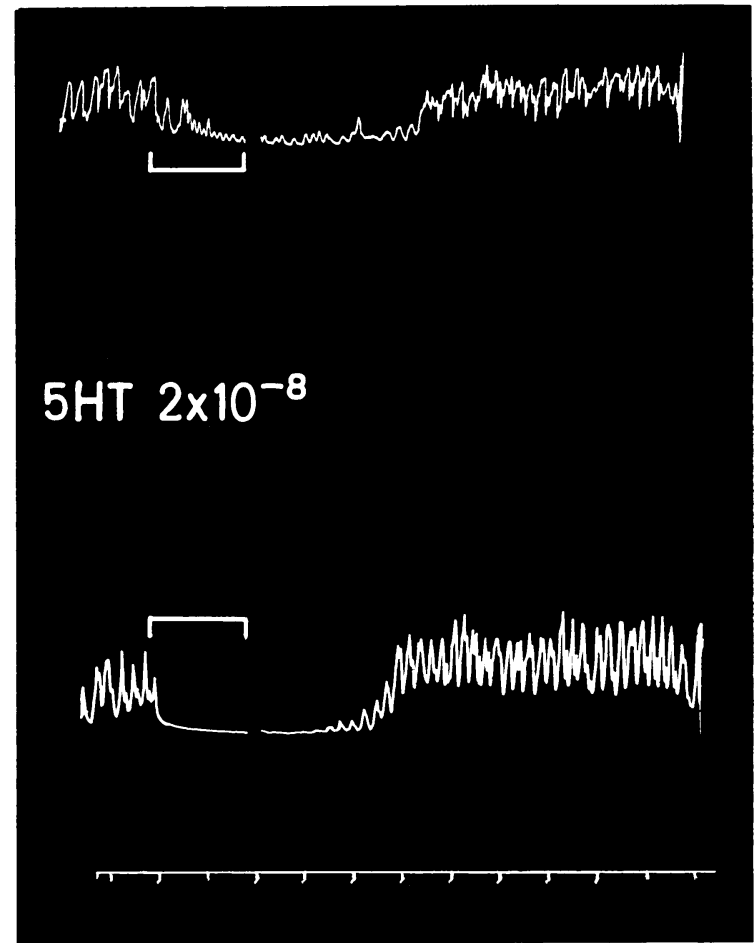

FIG. 8. Response of circular muscle to $5 H T 2 \times 10^{-8}$.

Longitudinal muscle, however, regularly responds to $5 \mathrm{HT}$ by a contraction which greatly exceeds the contact time of the drug. It is often preceded by a short inhibition but we have been unable to produce purely inhibition (Fig. 9). Many minutes are required for full relaxation and the response to a subsequent dose is much reduced if it follows within about 15 minutes of the first.

The response of longitudinal muscle to 5HT may thus seem similar to the response to nicotine or D.M.P.P., but, while the response to these drugs may be blocked by hexamethonium, the same preparation continues to respond to 5HT (Figs. 9 and 10). The response to $5 \mathrm{HT}$ may be blocked by 1 -methyl lysergic acid butanolamide $10^{-6}$ which spares the nicotine and D.M.P.P. response.

\section{DISCUSSION}

Human colon is thick tissue and even thin slices of the muscle are thicker than is usually favoured for full survival in an isolated system (Umbreit, Burris, and Stauffer, 1949). This may have several consequences. It may mean that drugs take longer to reach a threshold concentration in more deeply placed structures and the earliest response comes 

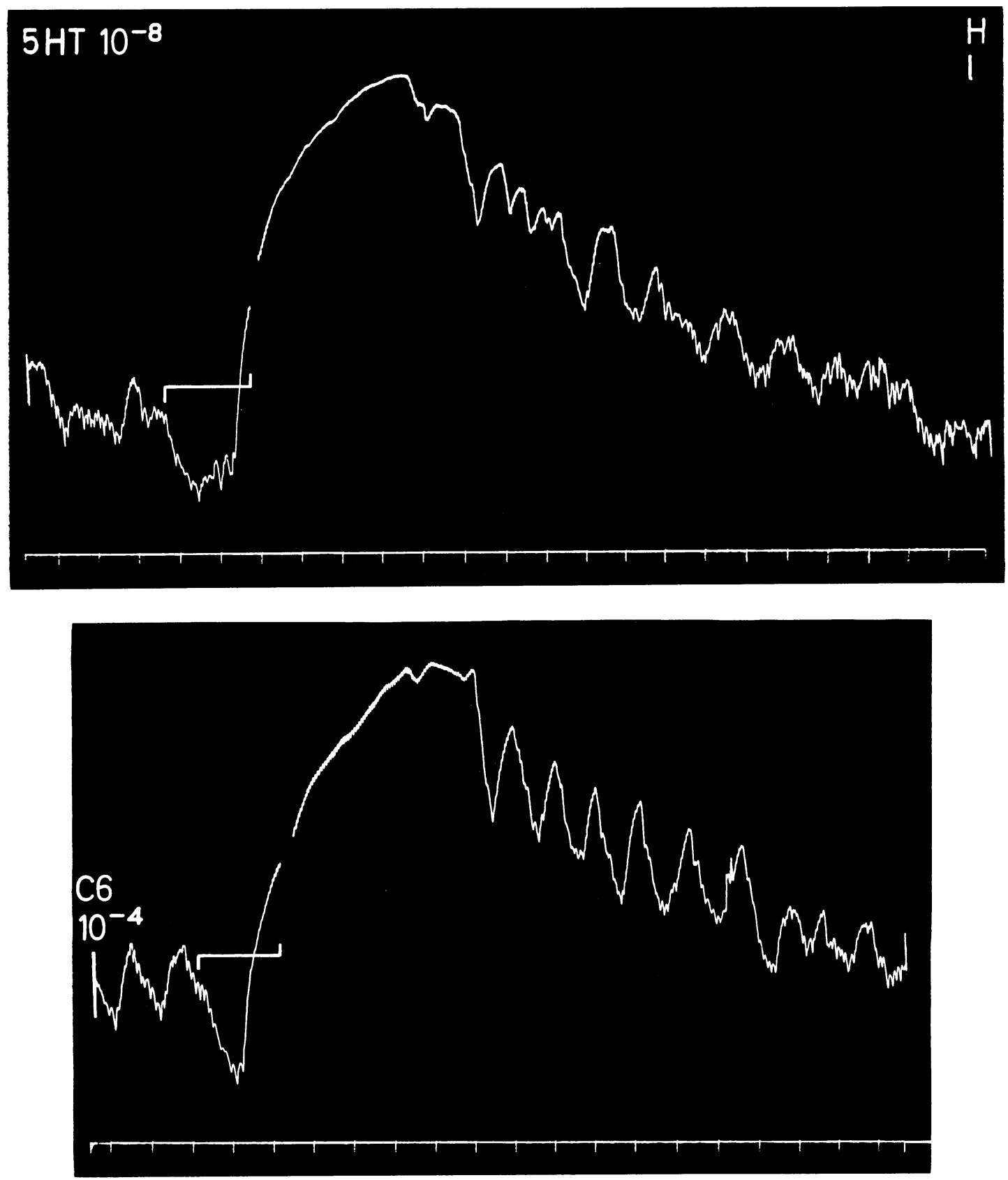

FIG. 9. Response of longitudinal muscle to 5HT 10 "alone and in the presence of hexamethonium II) ". 

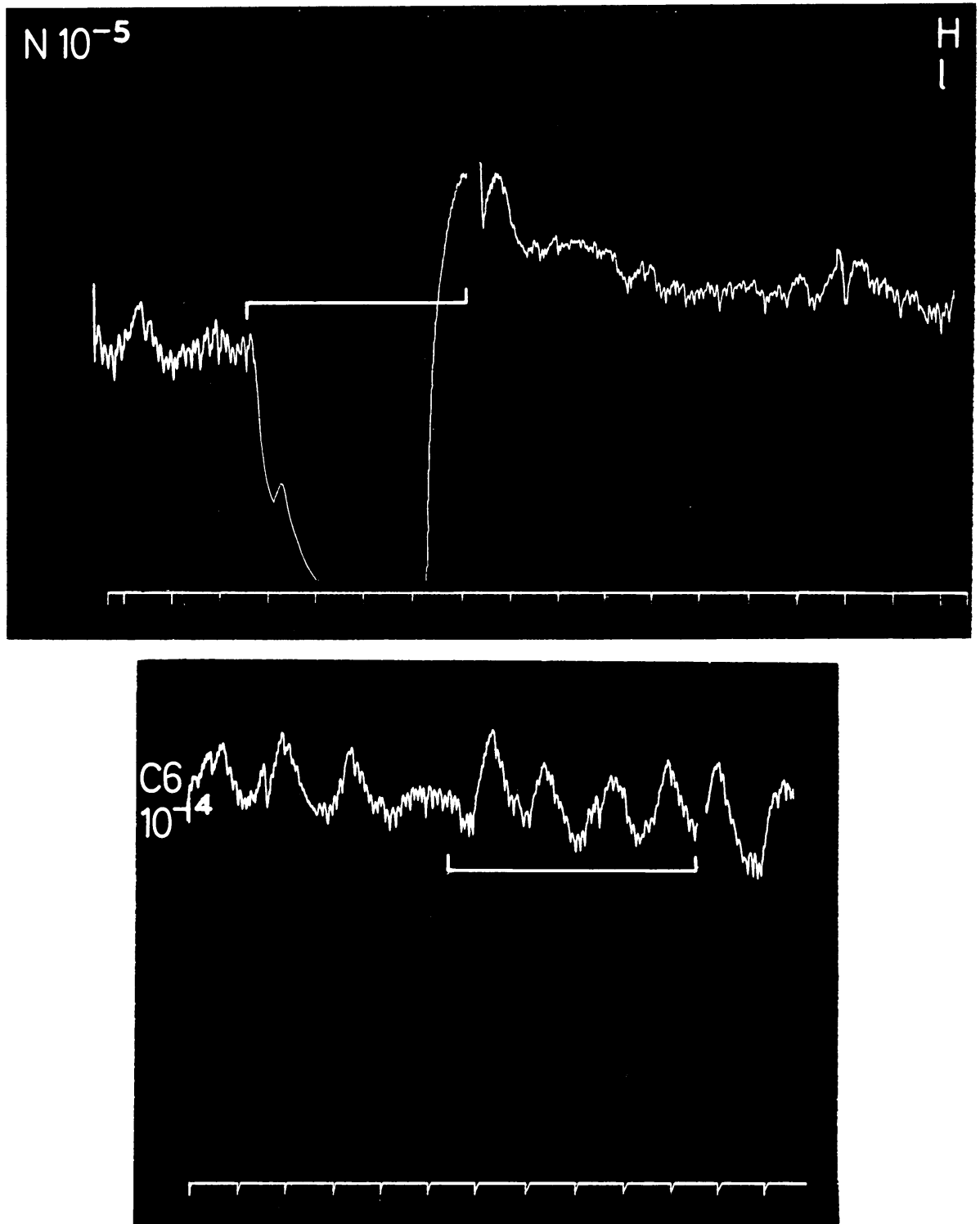

1ra. 10. Response of longitudinal muscle to nicotine to " alone and in the presence of heramethonium /0) '. Same prepratation as in Figure 9. 
from more superficial ones. This might explain the late appearance of the response we attribute to parasympathetic ganglionic stimulation and the time variation between different preparations. On the other hand this variation may reflect differences in local stores of transmitter substances. Another consequence may be that deeply placed nervous tissue suffers from anoxia, since Day and Vane (1963) have shown that it may be completely inactivated in this way. On one occasion during our earlier experiments four adjacent strips of muscle were set up. All responded to acetylcholine but only two could be caused to contract by nicotine. The preparations were later fixed and examined histologically. They were all identical and no variation in the numbers of ganglion cells could be seen. Tissue anoxia is a possible explanation in this instance.

Evans and Schild (1953) comment on the inconsistency which stripping of muscle coats from each other introduces into the normal regular response of longitudinal or circular strips of cat small intestine to drugs. In these human colon preparations the muscle coats are not separated but in making thin enough preparations variable damage may be introduced. Technical considerations may therefore influence the response of isolated human colonic muscle to drugs and contribute to the difference between our own conclusions and those of Fishlock and Parks (1963) and Bucknell and Whitney (1964).

We are making a detailed study in vivo and in vitro on animal primate colon which behaves very similarly to human colon in vitro. Our results may help resolve these differences.

Our experimental results are very similar to those obtained in the rabbit colon(Gillespie and Mackenna, 1960) where the stimulating drug effects were compared with the effect of stimulating sympathetic and parasympathetic nerves.

We consider therefore that normal human colonic muscle has in association with it adrenergic structures assumed to be post-ganglionic sympathetic nerves, which can be stimulated by nicotine or D.M.P.P. and cause inhibition. Furthermore, there are also cholinergic structures, assumed to be parasympathetic ganglion cells, and possibly nerve endings (Wright and Shepherd, 1965), which may similarly be stimulated. The net response to nicotine may be influenced by drugs affecting cholinergic or adrenergic systems but unspecific side effects must be guarded against (Boyd, Burnstock, Campbell, Jowett, O'Shea, and Wood, 1963). Bretylium preferentially blocks postganglionic sympathetic neurones (Boura and Green, 1959), but in our preparation we found no margin between the dose necessary to block completely the inhibitory response to nicotine or D.M.P.P. and that which also blocked the contractile response. Again pronethalol, which opposes the action of adrenaline (Black and Stephenson, 1962), can also block the contractile response at a concentration of $10^{-4}$. Neostigmine, except in very low concentrations, causes contraction itself, either due to the accumulation of endogenous acetylcholine from nervous and non-nervous structures (Feldberg and Lin, 1949) or by the liberation of acetylcholine from nerve endings (Carlyle, 1964). We have attempted to avoid non-specific side effects and our results suggest that both sympathetic and parasympathetic systems are present in human colon and man does not differ from other species in the response to nicotine and D.M.P.P. in vitro. Circular muscle from human colon is usually inhibited by 5-hydroxytryptamine (Fishlock, 1964) but the response would usually appear to be different in human circular and longitudinal muscle. Similarity between the response of longitudinal muscle to 5HT and nicotine or D.M.P.P. would appear to be superficial only. Further investigations are being carried out and suggest that the response to 5HT may be in part via nervous structures. A similar response has been observed and is being investigated in guinea-pig taenia by Akubue (1965, personal communication).

\section{SUMMARY}

The response to drugs in vitro of circular and longitudinal muscle strips from normal human sigmoid colon has been investigated.

An analysis of the effects of nicotine and D.M.P.P. suggests that both adrenergic and cholinergic systems are present.

The overall effect on the tissue may be influenced by the concentration of the drug and the duration of contact.

Longitudinal muscle is contracted by 5 -hydroxytryptamine but circular muscle is usually inhibited.

We are very grateful to the Medical Research Council for a grant for technical assistance (to P.G.W.), to the Wellcome Trust for a grant for equipment (to P.G.W.), and to Makere University College Council for a grant for expenses (to J.J.S.).

We wish to thank Parke Davis Ltd. for a gift of D.M.P.P. and Burroughs Wellcome Ltd. for a gift of bretylium.

\section{REFERENCES}

Akubue, J., (1965). Personal communication.

Black, J. W., and Stephenson, J. S. (1962). Pharmacology of a new adrenergic beta-receptor-blocking compound (Nethalide). Lancet, 2, 311-314.

Bodian, M., Stephens, F. D., and Ward, B. C. H. (1949). Hirschprung's disease and idiopathic megacolon. Ibid., 1, 6-11. 
Böhm, G., (1965). Personal communication.

Boura, A. L. A., and Green, A. F. (1959). The actions of bretylium: adrenergic neurone blocking and other effects. Brit. J. Pharmacol., 14, 536-548.

Boyd, H., Burnstock, G., Campbell, G., Jowett, A., O'Shea, J., and Wood, M. (1963). The cholinergic blocking action of adrenergic blocking agents in the pharmacological analysis of autonomic innervation. Ibid., 20, 418-435.

Bucknell, A., and Whitney, B. (1964). Effects of ganglion stimulating drugs on human isolated taenia coli. J. Physiol. (Lond.), 172, 50-51P.

Carlyle, R. F. (1964). The possibility that intracellular acetycholine maintains the inherent tone of the guinea-pig tracheal muscle. Ibid., 170, 56P.

Day, M., and Vane, J. R. (1963). An analysis of the direct and indirect actions of drugs on the isolated guinea-pig ileum. Brit. $J$. Pharmacol., 20, 150-170.

Evans, D. H. L., and Schild, H. O. (1953). The reactions of plexusfree circular muscle of cat jejunum to drugs. J. Physiol. (Lond.), 119, 376-399.

Feldberg, W., and Lin, R. C. Y. (1949). The effect of cocaine on the acetylcholine output of the intestinal wall. Ibid., 109, 475-487.
Fishlock, D. J. (1964). The action of 5-hydroxytryptamine on the circular muscle of the human ileum and colon in vitro. Ibid. 170, 11-12P.

- and Parks, A. G. (1963). A study of human colonic muscle in vitro. Brit. med. J., 2, 666-667.

Gillespie, J. S., and Mackenna, B. R. (1960). The inhibitory action of nicotine on the rabbit colon. J. Physiol. (Lond.), 152, 191-205.

Köberle, F. (1958). Megacolon. J. trop. Med. Hyg., 61, 21-24.

Shepherd, J. J., and Wright, P. G. (1965). Observations on megacolon. E. Afr. med. J., 42, 401.

Swenson, O., Neuhauser, E. B. D., and Pickett, L. K. (1949). New concepts of the etiology, diagnosis and treatment of congenital megacolon (Hirschprung's disease). Pediatrics, 4, 201-209.

Umbreit, W. W., Burris, R. H., and Stauffer, J. F. (1949). Manometric Techniques, 2nd ed., pp. 137-138. Burgess, Minneapolis.

Whitehouse, F. R., and Kernohan, J. W. (1948). Myenteric plexus in congenital megacolon. Study of eleven cases. Arch. intern. Med., 82, 75-111.

Wright, P. G., and Shepherd, J. J. (1965). The response to drugs of isolated human colonic muscle from a case of Hirschprung's disease. Lancet, 2, 1161-1163. 